\title{
Analisis Technology Readiness and Acceptance Model (TRAM) Pada Penggunaan Sport Wearable Technology
}

\author{
Heru Wijayanto Aripradono \\ Program Studi Teknologi Informasi, Universitas Internasional Batam, Batam, Kepulauan Riau \\ Email: heru.wijayanto@uib.ac.id
}

(Naskah masuk: 14 Januari 2021, direvisi: 8 Feb 2021, diterima: 19 Feb 2021)

\begin{abstract}
Abstrak
Pertumbuhan teknologi informasi tidak dapat dihindari terutama dalam mempengaruhi kehidupan sosial manusia saat ini. Inovasi yang dikembangkan secara tidak langsung memberikan dampak positif bagi kehidupan manusia saat ini. Wearable technology adalah salah satu teknologi yang tidak hanya memberikan banyak manfaat bagi kehidupan manusia, namun sangat membantu dalam menunjang aktivitas olahraga dan kesehatan. Wearable technology merupakan suatu teknologi komputer yang terhubung dengan koneksi internet, memiliki bentuk berupa aksesoris manusia sehari-hari yang dapat dikenakan pada tubuh mereka untuk memudahkannya dalam menerima notifikasi yang sudah terhubung dengan perangkat pintar lainnya. Pada penelitian ini akan melakukan identifkasi beberapa faktor yang mempengaruhi sudut pandang pengguna pada sports wearable technology serta untuk menginvestigasi penyebab pengadopsian konsumen pada teknologi tersebut berdasarkan teori Technology Readiness and Acceptance Model (TRAM). Penelitian ini menggunakan pendekatan kuantitatif dan variabel yang akan digunakan dalam penelitian ini adalah Positive Technology Readiness, Negative Readiness, Perceived Usefulness, Perceived Ease of Use, dan Intention to Use yang merupakan teori gabungan antara Technology Readiness and Acceptance Model (TRAM) untuk menjelaskan fenomena para pengguna terhadap penggunaan sports wearable sebagai fitness tracker mereka. Penelitian menggunakan komponen berbasis SEM dan kemudian dilakukan analisis menggunakan Partial Least Square. Penelitian ini menemukan bahwa pengguna memiliki penilaian positif (positive technology readiness) yang tinggi pada sports wearable technology melalui faktor Perceived Ease of Use (PEOU) dibandingkan dengan nilai Perceived Usefulness (PU) dalam wearable technology tersebut.
\end{abstract}

Kata Kunci: Technology Acceptance Model, Technology Readiness, Technology Readiness and Acceptance Model, Sports Wearable Technology

\section{Analysis of Technology Readiness and Acceptance Models for Sport Wearable Technology}

\begin{abstract}
The growth of information technology cannot be avoided, especially in influencing human social life today. The developed innovations have an indirect positive impact on human life today. Wearable technology is a technology that not only provides many benefits to human life, but is very helpful in supporting sports and health activities. Wearable technology is a computer technology connected to an internet connection, having a form of everyday human accessories that can be worn on their bodies to make it easier for them to receive notifications that are connected to other smart devices. This study will identify several factors that influence the user's point of view on sports wearable technology and to investigate the causes of consumer adoption of this technology based on the Technology Readiness and Acceptance Model (TRAM) theory. The research uses a quantitative approach and the variables that will be used in this research are Positive Technology Readiness, Negative Readiness, Perceived Usefulness, Perceived Ease of Use, and Intention to Use which is a combined theory between the Technology Readiness and Acceptance Model (TRAM) to explain the phenomenon of users towards use sports wearable as their fitness tracker. The study used SEM-based components and then analyzed using Partial Least Square. This study found that users gave high positive results (positive technology readiness) on wearable sports technology through the Perceived Ease of Use (PEOU) compared to the Perceived Usefulness (PU) value in the wearable technology.
\end{abstract}

Keywords: Technology Acceptance Model, Technology Readiness, Technology Readiness and Acceptance Model, Sports Wearable Technology 


\section{PENDAHULUAN}

Pertumbuhan teknologi informasi tidak dapat dihindari terutama dalam mempengaruhi kehidupan sosial manusia saat ini. Teknologi itu sendiri sudah menjadi bagian dalam kehidupan bermasyarakat saat ini dan menjadi bagian dari kehidupan manusia itu sendiri. Wearable technology adalah salah satu teknologi yang tidak hanya memberikan banyak manfaat bagi kehidupan manusia, namun sangat membantu dalam menunjang aktivitas olahraga dan kesehatan. Laporan yang dikeluarkan oleh World Economic Forum mengatakan bahwa peran wearable technology mampu memberikan kontribusi perubahan atau perkembangan pada dunia teknologi, serta bisa menjadi bagian penting dalam kehidupan manusia di masa yang akan datang [1]. Karena peran dan kontribusinya, beberapa perusahaan teknologi mulai melirik dan mulai mengembangkan produk yang terkait dengan wearable technology dan hal ini dibuktikan dari laporan International Data Corporation mengenai data pasar pengguna teknologi tersebut yang diprediksi akan bertambah sebanyak 15,3\%, dari 125,3 juta unit menjadi 198,5 juta unit pada akhir tahun 2019 dan jumlah ini akan terus meningkat hingga 279 juta unit pada akhir tahun 2023 [2].

Wearable technology merupakan suatu teknologi komputer yang terhubung dengan koneksi internet, memiliki bentuk berupa aksesoris manusia sehari hari yang dapat dikenakan pada tubuh mereka untuk memudahkannya dalam menerima notifikasi yang sudah terhubung dengan perangkat pintar lainnya [3]. Wearable Technology juga dapat dikatakan sebagai sebuah perangkat yang dapat dihubungkan dengan kulit tubuh manusia untuk secara terus menerus melakukan monitor terhadap aktivitas seseorang, namun tanpa mengganggu ataupun membatasi aktivitas penggunanya [4]. Teknologi ini secara umum mengacu pada perangkat teknologi elektronik, namun juga dapat mencakup produk seperti alat pintar (jam atau perangkat IoT lainnya) atau bahkan perangkat canggih yang digunakan dalam bahan pakaian atau alat pelindung [5].

Terdapat tiga ciri wearable technology menurut kegunaannya: teknologi yang mampu memberi notifikasi dimanapun penggunanya berada (contoh smartwatch), mampu menciptakan augmented reality (contoh Google Glass), serta mampu memantau atau merekam data segala aktivitas olahraga penggunanya [6]. Wearable technology pada bidang fitness dan wellness atau disebut dengan sports wearable technology merupakan salah satu penggunaan yang paling diminati saat ini, terutama ketika masyarakat dunia mulai memasuki masa pandemik dan mulai mempedulikan kesehatan dirinya dalam berolahraga untuk meningkatkan imunitas tubuhnya.

Sports wearable technology merupakan sebuah teknologi yang dikenakan pada bagian tubuh manusia ini memiliki fungsi dan sudah terhubung dengan aplikasi dalam device tertentu. Teknologi ini mampu merencanakan jadwal berolahraga, dapat mencatat dan mengolah data yang berikatan dengan kesehatan, serta mampu memberikan evaluasi berdasarkan kinerja yang telah dilakukan oleh pengguna [7]. Aplikasi yang paling populer digunakan adalah untuk memonitor jumlah langkah kaki yang ditempuh, mengetahui detak jantung, jumlah kalori yang terbuang, mengetahui durasi selama berolahraga, terdapat GPS untuk mengetahui daerah yang telah dilalui, serta mampu merekam pola tidur secara real-time atau dengan nama lainnya adalah fitness tracker yang diletakkan pada pergelangan tangan [8].

Karena sports wearable technology mampu memantau perilaku pengguna selama mereka melakukan olahraga dan menyediakan informasi yang berkaitan dengan kesehatan sangatlah cepat dan mudah, maka dengan menggunakan sports wearable technology serta memiliki pola hidup yang benar, dapat bantu menurunkan berat badan [9]. Selain itu, teknologi yang dapat dikenakan pada bagian pergelangan pengguna ini mampu meningkatkan penelitian biomedis dan memprediksi kardiovaskular serta metabolisme pada seseorang [10]. Dengan kehadirannya, diharapkan pengguna termotivasi untuk tetap aktif berolahraga, sehat, serta meningkatkan kualitas hidup mereka terutama dalam menghadapi masa pandemik akibat virus Covid-19 saat ini.

Pada awal tahun 2020, berdasarkan data yang dikeluarkan oleh We Are Social, pengguna internet di Indonesia mengalami peningkatan dibandingkan dengan tahun sebelumnya, yaitu sekitar 175,4 juta pengguna internet $(64 \%$ dari total populasi), dimana jumlah ini meningkat $17 \%$ dibandingkan tahun sebelumnya [11]. Terjadi peningkatan yang signifikan di masa pandemik Covid-19, yaitu sekitar $40 \%$ [12] dan ini membuat ketergantungan akan internet semakin besar.

Jika dikaitkan dengan penggunaan dan pertumbuhan sports wearable technology, Indonesia adalah salah satu negara yang memiliki potensi penjualan terbesar [13]. Hal ini dikarenakan konsumen Indonesia memiliki keinginan kuat untuk menggunakan serta mudah beradaptasi dengan perkembangan produk berbasis teknologi. Indonesia juga merasakan fungsi dari sports wearable technology sehingga kesadaran masyarakat akan gaya hidup sehat meningkat. Hal ini ditunjukkan dengan jumlah pengguna sports wearable technology, yang diperkirakan akan meningkat hingga 21,4 juta pada tahun 2021 dan jumlah ini diperkirakan akan meningkat sekitar $11,4 \%$ dibandingkan tahun sebelumnya [14].

Meskipun demikian, jika dilihat dari grafik Difussion of Innovations, keberadaan teknologi sports wearable technology masih berada dalam early stage serta kebanyakan dari pengguna merasa bosan, tidak tertarik lagi jika tujuan dan rasa keingintahuan mereka sudah tercapai semua, atau dengan kata lain cepat bosan [15]. Hal ini terjadi karena yang membeli dan memiliki sports wearable technology adalah pengguna yang memiliki high income sehingga teknologi tersebut masih dianggap mahal atau seseorang yang sudah sadar akan pentingnya menjaga kesehatan serta paham akan teknologi. Hal lainnya adalah pengguna harus intensif atau penggunaan dalam waktu jangka panjang untuk bisa merasakan manfaat yang ditawarkan. Oleh karena itu dengan pemahaman akan adopsi serta menggunakan sports wearable technology dengan mendalam bisa memiliki pengaruh yang baik untuk meningkatkan kualitas hidup mereka [16]. 
Berkaitan dengan perkembangan teknologi seperti salah satunya sport wearable technology, maka diperlukan penelitian mengenai penerimaan teknologi terbaru agar pemanfaatan dan kemudahan yang ditawarkan dapat dirasakan oleh pengguna. Teori yang digunakan untuk mengetahui pengadopsian teknologi tersebut adalah Technology Acceptance Model (TAM) [17]. TAM merupakan suatu teori dasar untuk mengeksplorasi penerimaan atau pengadopsian pengguna terhadap teknologi tertentu [7]. Selain itu, TAM merupakan sebuah teori yang menjelaskan proses bagaimana penerimaan teknologi terbaru berdasarkan menggunakan dua konsep atau belief yaitu Perceived Usefulness (PU) dan Perceived Ease of Use (PEU) [18].

Perceived Usefulness (PU) merupakan suatu tingkat kepercayaan yang dimiliki oleh tiap individu secara subjektif bahwa pengguna percaya menggunakan teknologi tertentu dapat meningkatkan kinerja mereka [6]. Sedangkan Perceived Ease of Use (PEU) merupakan keyakinan subyektif yang dimiliki oleh pengguna bahwa dengan menggunakan sebuah teknologi untuk tujuan tertentu, maka akan mengurangi usaha seseorang dari sebelum menggunakannya [18]. Sikap seseorang pada penerimaan sebuah teknologi ditentukan oleh sejauh mana mereka merasakan suatu sistem/teknologi itu berguna atau mudah digunakan bagi mereka atau tidak.

Baik PU maupun PEU, keduanya berperan sebagai prediktor terhadap niat perilaku para pengguna secara signifikan [6]. Semakin mudah teknologi digunakan, maka teknologi tersebut akan semakin bermanfaat kedepannya [19]. Jadi dapat disimpulkan, bahwa ketika pengguna merasakan kemudahan dan pemanfaatan dalam menggunakan teknologi, maka individu tersebut akan mudah menerima dan mengadopsinya untuk tujuan tertentu.

Meskipun beberapa penelitian yang telah dilakukan dan menggunakan teori Technology Acceptance Model dalam penerimaan teknologi, namun teori tersebut memiliki kelemahan dimana Technology Acceptance Model tidak cukup menjelaskan perilaku adopsi pengguna dari sisi psikologi [20]. Teori Technology Acceptance Model tidak dapat mengakomodasi peranan orang di sekitarnya dalam memengaruhi perilaku individu, tidak menjelaskan perbedaan tiap individu dalam berperilaku, dan tidak mempertimbangkan peranan dari kemampuan seseorang untuk merealisasikan setiap keinginan [20]. Maka dari itu, banyak penelitian telah menyarankan perlunya perluasan untuk menambahkan konstruk atau variabel dari teori psikologis terhadap penenerimaan teknologi terbaru [21].

Model perpaduan antara Technology Readiness and Acceptance Model (TRAM), merupakan salah satu model yang memperluas teori Technology Acceptance Model dengan mengintegrasikan variabel Technology Readiness (TR) dalam penerimaan suatu teknologi baru [20]. Technology Readiness merupakan suatu kepercayaan tiap individu tentang kecenderungan dalam menggunakan suatu produk atau sistem berbasis teknologi. Dengan penambahan Technology Readiness dalam Technology Readiness and Acceptance Model (TRAM) merupakan konstruk yang menggambarkan keadaan pengguna dalam menerima suatu produk atau sistem berbasis teknologi lebih spesifik. Pengaplikasian Technology
Readiness dan Acceptance Model dalam penelitian dapat mengidentifikasi atau memahami proses psikologis pengguna terhadap penerimaan sebuah produk atau sistem berbasis teknologi [7], [20], [22].

Adanya perubahan profil konsumen Indonesia dan perkembangan sports wearable technology di Indonesia, maka penelitian pada teknologi tersebut menjadi penting dilakukan mengingat teknologi ini masih termasuk kategori produk early stage sehingga dibutuhkan penelitian lebih lanjut dengan menggunakan TRAM. Penelitian menggunakan TRAM bertujuan untuk mengidentifikasikan penerimaan atau keputusan konsumen secara psikologis pada penerimaan sport wearable technology, terutama pada penggunaan fitness tracker. TRAM mampu menjelaskan dan menghubungkan dari sisi sudut pandang pendapat pribadi (optimism, innovativeness, discomfort, insecurity) dan cara kerja sebuah teknologi (Perceived Usefulness dan Perceived Ease of Use) pada pengadopsian dalam kehidupan penggunanya (Intention to Use) [23].

Berdasarkan latar belakang, maka rumusan masalah dalam penelitian ini adalah bagaimana penerimaan konsumen berdasarkan teori Technology Readiness and Acceptance Model (TRAM) pada pengguna sports wearable technology di Indonesia?

\section{METODOLOGI PENELITIAN}

\section{A. Desain Penelitian}

Penelitian ini menggunakan pendekatan kuanititatif. Penelitian kuantitatif merupakan penelitian yang didasarkan pada filsafat post-postivis yang akan melihat sebuah fenomena/gejala/realitas dapat terukur oleh angka-angka dan hasilnya dapat diklasifikasikan melalui analisis statistik [24]. Membuat hipotesis (praduga sementara) sebagai acuan dari data yang dibutuhkan untuk menganalisis instrumen yang telah ditentukan merupakan bagian dari penelitian kuantitatif. Penelitian ini menggunakan jenis penelitan eksplanatori dimana peneliti mengidentifikasi faktor-faktor kausif variabel bebas (x) terhadap variabel terkait (y) [25].

Variabel yang digunakan dalam penelitian ini adalah Positive Technology Readiness (PTR), Negative Technology Readiness (NTR), Perceived Usefulness (PU), Perceived Ease of Use (PEOU), dan Intention to Use (INT) sesuai dengan teori gabungan antara Technology Readiness and Acceptance Model (TRAM) untuk menjelaskan fenomena para pengguna terhadap penggunaan sports wearable sebagai fitness tracker mereka. Penelitian ini menggunakan cross sectional karena data primer dikumpulkan dalam satu rangkaian waktu melalui kuesioner [26].

\section{B. Model Penelitian}

Model penelitian menggunakan penelitian yang dilakukan oleh Kim dan Chiu mengenai penerimaan konsumen terhadap pengguna sports wearable technology di Korea Selatan menggunakan Technology Readiness and Acceptance Model (TRAM) [7]. Ada beberapa research gap yang ingin diangkat dalam penelitian ini, pertama adalah terkait dengan spesifik 
tujuan dan tempat pengambilan data responden yang menggunakan teknologi tersebut. Jika Kim dan Chiu meneliti terhadap pengguna yang menggunakan aplikasi running saja [7], maka dalam penelitian ini adalah pengguna yang menggunakan semua aplikasi fitness tracker pada sports wearable technology. Kedua, adalah mengenai kondisi dan keadaan dua negara (Korea Selatan dan Indonesia), yang memiliki perbedaan budaya dan pola pikir cara menanggapi serta cara mengadopsi sebuah produk atau sistem berbasis teknologi. Model penelitian yang dikembangkan oleh Kim \& Ciu adalah sebagai berikut:

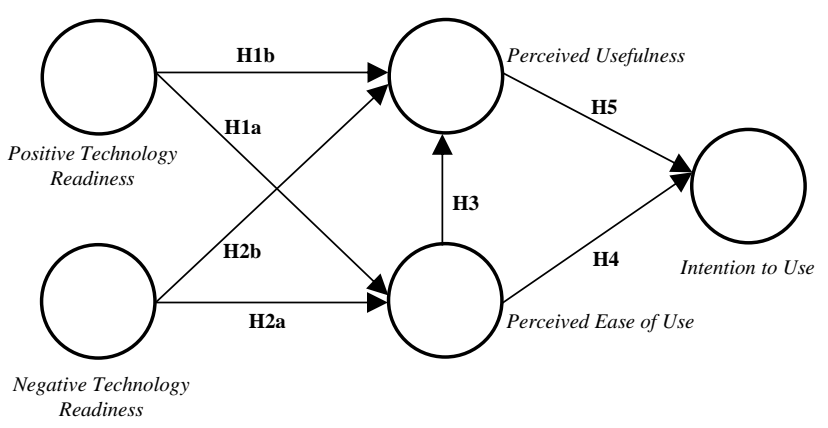

Gambar 1. Model Penelitian [7]

\section{Variabel Penelitian}

Variabel independen dalam Structural Equation Modeling disebut sebagai variabel laten eksogen (X) yang merupakan variabel yang memengaruhi dan menjadi sebab timbulnya dan atau perubahan pada variabel manifes. Variabel laten eksogen pertama yaitu Technology Readiness, yang dibagi menjadi Positive Technology Readiness (X1) dan dibagi menjadi 2 yaitu Optimism (X1a) dan Innovativeness (X1b), variabel laten eksogen kedua adalah Negative Technology Readiness (X2) dibagi menjadi 2 juga yaitu Insecurity (X2a) dan Discomfort (X2b). Serta variabel dari Acceptance Model yaitu Perceived Usefulness (X3) dan Perceived Ease of Use (X4). Selain variabel laten endogen, acceptance model menjadi variabel variabel intervening atau mediator, dimana variabel ini yang menjadi penghubung antara variabel eksogen dengan endogen. Variabel dependen dalam SEM disebut variabel laten endogen (Y) dan merupakan variabel yang dipengaruhi serta diprediksi dari variabel laten eksogen. Penelitian ini memiliki variabel laten endogennya yang merupakan bagian terakhir dari acceptance model yaitu Intention to Use (Y). Definisi operasional indikator variabel yang digunakan dalam kuesioner penelitian ini adalah sebagai berikut:

Tabel 1. Definisi Operasional Indikator Variabel [7]

\begin{tabular}{cl}
\hline Nomor & \multicolumn{1}{c}{ Definisi Operasional Indikator Variabel } \\
\hline Variabel Positive Technology Readiness - Optimism \\
\hline 1 & $\begin{array}{l}\text { Responden berpikir menggunakan teknologi } \\
\text { adalah ide yang bagus. }\end{array}$ \\
\hline 2 & $\begin{array}{l}\text { Responden lebih memilih menggunakan } \\
\text { teknologi paling terbaru dalam kesehariannya. }\end{array}$ \\
\hline 3 & $\begin{array}{l}\text { Responden merasa dengan menggunakan } \\
\text { teknologi hasil pekerjannya menjadi lebih } \\
\text { banyak dari tidak menggunakannya. }\end{array}$ \\
\hline
\end{tabular}

\begin{tabular}{|c|c|}
\hline 4 & $\begin{array}{lccc}\text { Responden } & \text { merasa } & \text { dengan } & \text { menggunakan } \\
\text { teknologi mereka bisa } & \text { menyelesaikan } \\
\text { pekerjaannya darimana saja tanpa batas. }\end{array}$ \\
\hline \multicolumn{2}{|r|}{$\begin{array}{c}\text { Variabel Positive Technology Readiness - } \\
\text { Innovativeness }\end{array}$} \\
\hline 5 & $\begin{array}{l}\text { Responden merasa mereka adalah sumber } \\
\text { informasi mengenai perkembangan teknologi }\end{array}$ \\
\hline 6 & $\begin{array}{l}\text { Responden merasa mereka bisa mendapatkan } \\
\text { informasi terbaru seputar perkembangan } \\
\text { teknologi tanpa bantuan orang lain. }\end{array}$ \\
\hline 7 & $\begin{array}{l}\text { Responden merasa selalu } \\
\text { perkembangan seputar teknologi }\end{array}$ \\
\hline \multicolumn{2}{|c|}{ Variabel Negative Technology Readiness - Insecurity } \\
\hline 8 & $\begin{array}{l}\text { Responden merasa tidak aman untuk } \\
\text { memberikan informasi secara online }\end{array}$ \\
\hline 9 & $\begin{array}{l}\text { Responden merasa tidak berani untuk } \\
\text { memberikan nomor kartu kredit secara online }\end{array}$ \\
\hline 10 & $\begin{array}{l}\text { Responden merasa sistem keamanan tidak aman } \\
\text { saat melakukan transaksi bisnis keuangan } \\
\text { melalui online }\end{array}$ \\
\hline 11 & $\begin{array}{l}\text { Responden merasa tidak aman jika setiap } \\
\text { transaksi secara online tidak ada tanda terima }\end{array}$ \\
\hline \multicolumn{2}{|c|}{ Variabel Negative Techology Readiness - Discomfort } \\
\hline 12 & $\begin{array}{l}\text { Responden merasa harus hati-hati setiap } \\
\text { pergantian teknologi dimana cara kerja mereka } \\
\text { telah diubah olehnya }\end{array}$ \\
\hline 13 & $\begin{array}{l}\text { Responden merasa teknologi bisa memberikan } \\
\text { dampak yang buruk terhadap kesehatannya }\end{array}$ \\
\hline 14 & $\begin{array}{l}\text { Responden merasa data pribadi mereka bisa } \\
\text { diintai oleh oleh lembaga tertentu. }\end{array}$ \\
\hline \multicolumn{2}{|r|}{ Variabel Perceived Usefulness } \\
\hline 15 & $\begin{array}{l}\text { Responden merasakan bahwa sports wearable } \\
\text { dapat meningkatan durasi saat olahraga. }\end{array}$ \\
\hline 16 & $\begin{array}{l}\text { Responden merasa sports wearable mampu } \\
\text { meningkatkan perubahan yang positif. }\end{array}$ \\
\hline 17 & $\begin{array}{l}\text { Responden merasa sports wearable mampu } \\
\text { menambah intensitas saat olahraga. }\end{array}$ \\
\hline 18 & $\begin{array}{l}\text { Responden merasa sports } \\
\text { mendapatkan manfaat yang baik. }\end{array}$ \\
\hline \multicolumn{2}{|r|}{ Variabel Perceived Ease of Use } \\
\hline & $\begin{array}{l}\text { Responden merasa sports wearable mudah } \\
\text { digunakan sehari-hari. }\end{array}$ \\
\hline 20 & $\begin{array}{l}\text { Responden merasa sports wearable mudah } \\
\text { dipelajari. }\end{array}$ \\
\hline 21 & $\begin{array}{l}\text { Responden merasa interaksi sports wearable } \\
\text { mudah dipahami. }\end{array}$ \\
\hline 22 & $\begin{array}{l}\text { Responden merasa mengoperasikan sports } \\
\text { wearable mudah. }\end{array}$ \\
\hline \multicolumn{2}{|r|}{ Variabel Intention to Use } \\
\hline 23 & $\begin{array}{l}\text { Prediksi responden terhadap terus penggunaan } \\
\text { sports wearable di masa depan. }\end{array}$ \\
\hline 24 & $\begin{array}{l}\text { Prediksi responden akan sering terus } \\
\text { menggunakan sports wearable di masa depan } \\
\text { dibandingkan saat ini. }\end{array}$ \\
\hline 25 & $\begin{array}{l}\text { Responden bermaksud untuk terus menggunakan } \\
\text { sports wearable di masa depan. }\end{array}$ \\
\hline
\end{tabular}


26 Responden menduga mereka akan terus menggunakan sports wearable dimasa depan.

D. Populasi dan Sampel

Populasi adalah wilayah penelitian yang memiliki kualitas dan karakter tertentu dimana sudah ditentukan oleh peneliti sehingga dapat diambil kesimpulannya [24]. Populasi dalam penelitian ini adalah pengguna sport wearable khususnya yang dikenakan pada pergelangan (wrist worn) yang tinggal dan berasal dari Indonesia. Berkaitan dengan kriteria tersebut, populasi dalam penelitian ini tidak dapat ditentukan jumlahnya secara pasti.

Sampel merupakan sebagian atau jumlah karakteristik yang dipunyai oleh populasi yang sudah dipilih oleh peneliti [24]. Sampel yang dibutuhkan dalam penelitian Structure Equation Modeling (SEM) adalah berjumlah 5-10 kali dari jumlah indikator variabel dalam kuesioner untuk membuat data [27]. Maka penelitian ini akan mengacu pada Kline dimana jumlah item kuesioner (26 item) dikalikan 5. Jadi minimal sampel dalam penelitian ini adalah sebanyak 130 responden.

Teknik pengambilan sampel pada penelitian ini menggunakan purposive sampling, yang merupakan teknik sampling dengan memiliki pertimbangan sesuai dengan ciri dan spesifik karakteristik yang sudah ditetapkan oleh peneliti. Karakteristik yang dipilih adalah (1) pengguna harus memiliki dan menggunakan sports wearable yang dapat dikenakan pada pergelangan, (2) pengguna harus menggunakan aplikasi fitness tracker (menghitung jumlah langkah kaki, perekam detak jantung, GPS untuk melacak keberadaan pengguna saat berolahraga, dan goal coach) terhadap teknologi tersebut saat mereka melakukan olahraga, (3) dan pengguna harus berasal dan tinggal di wilayah Indonesia.

\section{E. Teknik Analisis Data}

Penelitian ini menggunakan empat langkah analisis data [28] dalam PLS, yaitu sebagai berikut :

1. Merancang Model Struktural (inner model)

Tahap pertama yang dilakukan adalah dengan merancang model struktural yang memiliki hubungan antar variabel laten dan didasari dengan rumusan masalah atau hipotesis penelitian. Inner model adalah hubungan detail antar variabel laten dan disebut juga dengan inner relation, bertujuan untuk dapat mendeskripsikan hubungan antara variabel laten berdasarkan teori penelitian yang digunakan.

2. Merancang Model Pengukuran (outer model)

Langkah berikutnya adalah melakukan perancangan model pengukuran karena berhubungan dengan apakah sebuah indikator bersifat reflektif atau formatif. Model pengukuran sendiri merupakan spesifikasi hubungan yang dibangun antar variabel laten dengan tiap indikatornya dan disebut dengan measurement model, yang tujuannya adalah mendefinisikan karateristik konstruk dengan variabel manifesnya.

3. Mengkonstruksi Diagram Jalur

Langkah selanjutnya untuk mendapatkan hasil adalah dengan menggunakan diagram jalur.
4. Uji Outer Model dan Inner Model

a. Outer Model

i. Uji Validitas

Tahap pertama adalah dengan melakukan Content Validty/Logical Validty yang dilakukan dengan melakukan pre-test kuesioner penelitian dimana untuk mengetahui sejauh mana item-item yang digunakan dalam penelitian mudah dipahami secara logika dan apakah sudah sesuai dengan apa yang akan diukur atau belum. Kemudian melakukan Construct Validity untuk memperlihatkan seberapa jauh tiap item pernyataan mampu mengukur apa yang akan diukur sesuai dengan definisi konseptual yang sudah ditetapkan.

ii. Uji Reliabilitas

Pada tahapan uji reliabilitas dilakukan dengan melakukan pengukuran terhadap variabel, dimana diharapkan memiliki nilai $\geq 0,70$, yang berarti variabel tersebut memiliki reliabilitas yang baik.

b. Inner Model

Tujuannya mengetahui hubungan antar variabel laten. Dalam melakukan ujian ini terdapat dua langkah, yaitu sebagai berikut:

i. $R$-Square

Dengan melihat nilai $R$-Square tiap konstruk endogen dimana nilai $R$-Square yang semakin tinggi atau mendekati $100 \%(1,00)$ maka semakin baik variabel endogen yang diterangkan oleh tiap variabelnya.

ii. Path Coefficients

Nilai path coefficients dan $t$-statistic atau $t$-value sendiri dapat dilihat dari hasil pengolahan bootstrapping dengan menggunakan metode resampling bootstrap. Path coefficients dalam pemodelan itu sendiri harus memiliki nilai $t$ Statistic yang lebih besar dari nilai sebesar 1,96 dan didapatkan dari tabel-t, dimana dalam penelitian ini menggunakan tingkat kepercayaan sebesar $5 \%$. Jika hasil pengujiannya adalah signifikan, maka memiliki pengaruh antara variabel laten terhadap variabel lainnya. Jika nilai ini positif, maka pengaruh antara variabel tersebut positif dan begitu juga sebaliknya.

\section{ANALISIS DAN PEMBAHASAN}

Teknik purposive sampling dan non-probability akan digunakan dalam penelitian ini, dimana terdapat beberapa karakteristik responden yang mampu mengisi tiap butir pernyataan kuesioner yang telah dibuat. Kriteria responden dalam penelitian ini memiliki tiga buah kategori atau karakteristik. Karakteristik yang dipilih adalah (1) pengguna harus memiliki dan menggunakan sports wearable yang dapat dikenakan pada pergelangan, (2) pengguna harus menggunakan aplikasi fitness tracker (menghitung jumlah langkah kaki, perekam detak jantung, GPS untuk melacak keberadaan pengguna saat berolahraga, dan goal coach) 
terhadap teknologi tersebut saat mereka melakukan olahraga, (3) dan pengguna harus berasal dan tinggal di wilayah Indonesia. Penyebaran kuesioner dilakukan kurang lebih selama 30 hari di bulan Agustus-September 2020.

Total keseluruhan responden dalam penelitian ini adalah 195 responden, namun karena 23 responden tidak memenuhi syarat dalam penelitian atau tidak pernah menggunakan sports wearable technology sebagai fitness tracker minimal 2 kali pemakaian, maka jumlah tersebut tidak dimasukan ke dalam penelitian, sehingga total responden yang akan diteliti pada penelitian ini sebanyak 172 yang dapat dianalisis. Jumlah angka ini sesuai dengan syarat sampel dengan menggunakan teknik SEM pada diskrepansi Maximum Likelihood, yaitu setiap indikator dikalikan dengan 5 serta harus berada pada kisaran 100-200, sesuai juga dengan syarat minimal sampel dengan menggunakan teknik PLS yaitu pada kisaran 30 . Penyebaran kuesioner dilakukan secara online dengan menggunakan software Survey Monkey.

Berdasarkan hasil penyebaran kuesioner, didapatkan responden berjumlah 172 responden, dimana didapatkan penyebaran respondennya berdasarkan jenis kelamin pada penelitian ini adalah $55 \%$ pria ( 95 responden) dan $45 \%$ wanita (77 responden). Sedangkan karakteristik responden berdasarkan kelompok usia adalah sebagai berikut:

Tabel 2. Karakteristik Responden Berdasarkan Kelompok Usia

\begin{tabular}{lrr}
\hline Kelompok Usia & \multicolumn{1}{c}{ Jumlah } & Persentase \\
\hline $18-24$ & 58 & $34 \%$ \\
\hline $25-34$ & 85 & $49 \%$ \\
\hline $35-44$ & 16 & $9 \%$ \\
\hline $45-54$ & 13 & $8 \%$ \\
\hline Total & $\mathbf{1 7 2}$ & $\mathbf{1 0 0 \%}$ \\
\hline
\end{tabular}

Berdasarkan Tabel 2, dapat dilihat bahwa pengguna sports wearable kebanyakan adalah laki-laki rentang usia 1834 tahun atau generasi millennials karena pada umumnya mereka memiliki frekuensi untuk sering berolahraga/beraktivitas dan masih bisa dilakukan dengan intens, serta mereka sangat nyaman belajar dan mudah beradaptasi dengan teknologi terbaru. Kemudian pada umumnya generasi millenials lebih mudah untuk mengerti hal-hal baru, terutama teknologi, karena mereka memiliki jiwa keingintahuan yang tinggi akan suatu produk teknologi baru.

Uji outer model atau measurement model ini bertujuan untuk menjelaskan bagaimana tiap indikator berhubungan dengan variabel latennya [28]. Untuk melakukan uji model pengukuran, terdapat dua tahapan yang harus dilalui yaitu dengan melakukan uji validitas dan uji realibilitas. Untuk melakukan kedua uji tersebut, peneliti terlebih dahulu mengolah data sebanyak 172 responden dengan menggunkan software SmartPLS 3.0. Berikut ini adalah hasil olah data berupa diagram jalur dalam penelitian yang dilakukan.

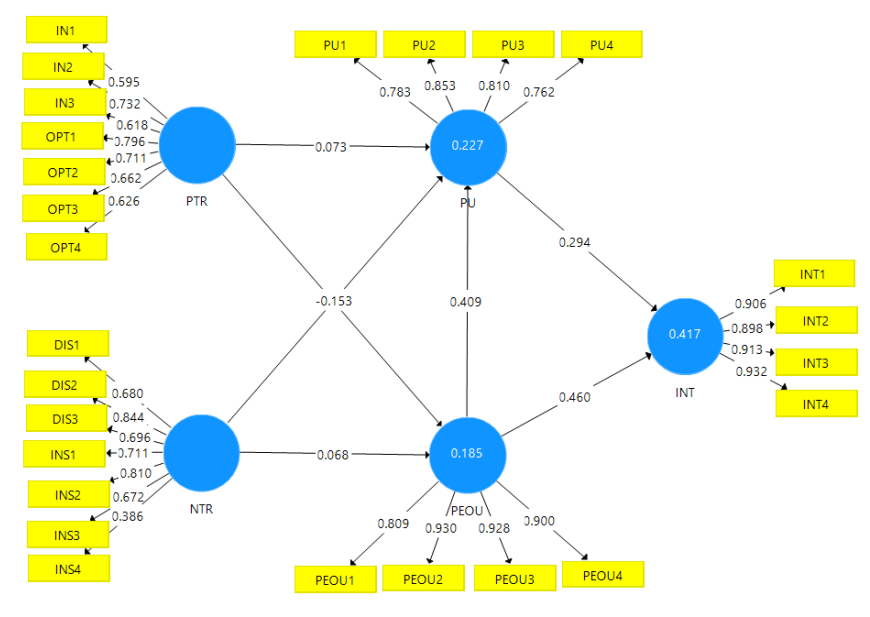

Gambar 2. Diagram Jalur Awal

Dapat dilihat dari pemodelan gambar di atas, terdapat 5 konstruk dengan total indikator sebanyak 26 items pernyataan atau indikator yang diteliti dalam penelitian ini. Kelima konstruk digambarkan dengan bentuk lingkaran dan 26 indikator digambarkan dengan kotak. Kelima variabel tersebut terdiri dari 4 variabel eksogen serta 1 variabel endogen. Keempat variabel eksogen diantaranya adalah Positive Technology Readiness (PTR), Negative Technology Readiness (NTR), Perceived Usefulness (PU), dan Perceived Ease of Use (PEOU). Untuk variabel endogennya adalah Intention to Use (INT).

Angka yang ada di dalam garis yang menghubungkan antar tiap konstruk atau variabel (yang berbentuk lingkaran) dengan indikatornya (yang berbentuk kotak) merupakan sebuah nilai outer loading/loading factor yang menunjukkan besarnya korelasi antara indikator dengan konstruknya. Misalnya angka 0,906 yang terdapat pada garis penghubung antara konstruk INT dengan salah satu indikatornya INT1.

Berikutnya adalah untuk angka-angka yang terdapat pada garis penghubung antara konstruk (variabel) dengan konstruk lainnya yang berbentuk lingkaran, merupakan nilai dari path coefficients yang menunjukkan besarnya korelasi/hubungan pengaruh antara satu konstruk dengan konstruk lainnya. Misalnya angka 0,294 yang terdapat pada garis yang menghubungkan antara konstruk PU dengan konstruk INT.

Kemudian yang terakhir, untuk tiap angka yang berada dalam konstruk atau variabel berupa angka 0,227 di dalam konstruk PU dan 0,417 dalam konstruk INT merupakan nilai $R$-Square yang menunjukkan seberapa besar konstribusi dari variabel independen terhadap variabel dependen. Langkah selanjutnya yang akan dilakukan berdasarkan dari gambar di atas, peneliti akan melakukan uji validitas dan reliabilitas pada pemodelan tersebut.

Dalam menguji validitas ini, nilai yang harus dimiliki oleh tiap konstruk adalah $\geq 0,60$. Nilai yang melebihi dari angka yang telah ditetapkan menunjukkan bahwa tiap indikator memiliki validitas konvergen yang dapat diterima dan memiliki nilai yang baik [28].

Pada uji validitas ini, ternyata terdapat 3 indikator yang tidak valid dari total 26 item kuesioner karena memiliki nilai 
outer loading lebih kecil dari yang disyaratkan yaitu sebesar 0,6. Dikarenakan indikator tersebut tidak valid maka harus di eliminasi dari model diagram jalur penelitian karena dapat memengaruhi hasil penelitian. Maka peneliti, mengolah datanya kembali sampai semua indikator memenuhi syarat. Dengan pengurangan ketiga indikator dari total 26, maka total indikator saat ini menjadi sebanyak 23 item. Ketiga indikator tersebut adalah sebagai berikut IN1 (nilai outer loading 0,595), IN3 (nilai outer loading 0,576) dan INS4 (nilai outer loading 0,386).

Dari ketiga indikator ini, memiliki nilai dibawah 0,6 sehingga indikator tersebut tidak valid dan harus dieliminasi dari pemodelan diagram jalur penelitian, karena dapat mempengaruhi hasil penelitian yang dilakukan. Salah satu kemungkinan yang membuat indikator tersebut tidak valid adalah beragamnya dan luasnya lokasi dari responden di Indonesia sehingga dapat menyebabkan adanya perbedaan aspek kognisi atau pemahaman dalam sebuah kuesioner penelitan dari sisi perbedaan budaya dan komunikasi [29]. Dengan demikian pemodelan diagram jalurnya menjadi seperti pada Gambar 3.

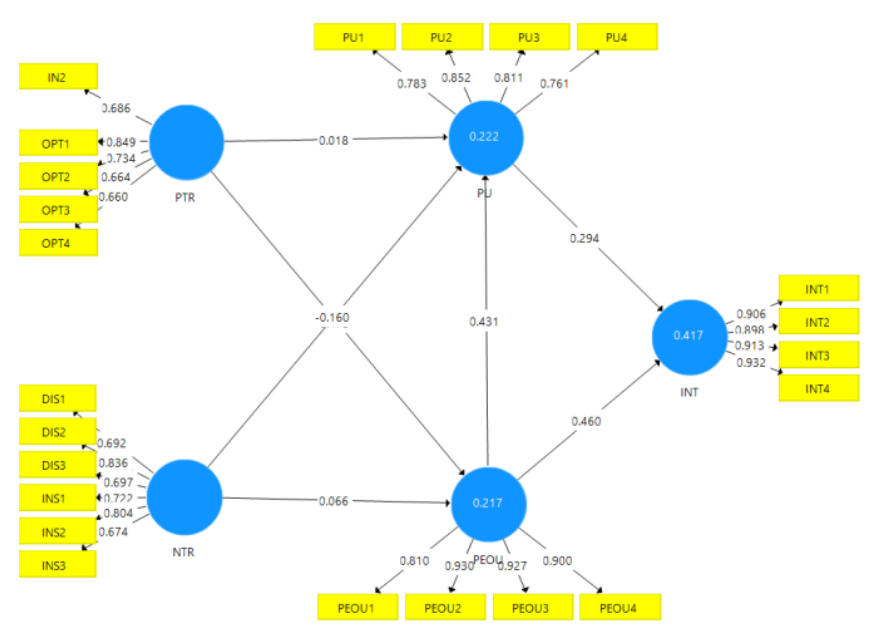

Gambar 3. Diagram Jalur Akhir

Selain menguji validitas dari sisi nilai outer loading, terdapat juga uji validitas konvergen yang dilakukan melalui nilai Average Variance Extracted (AVE). Nilai AVE menunjukkan bahwa gabungan item yang mengukur suatu konstruk bersatu atau tidak yang artinya memiliki validitas konvergen atau tidak serta nilai AVE ini dikatakan baik jika memiliki nilainya lebih dari 0,5 . Pada Tabel 3 akan diperlihatkan bagaimana nilai tabel AVE dari setiap variabel dalam penelitian ini.

Tabel 3. Nilai Average Variance Extracted (AVE) 5 Variabel

\begin{tabular}{lr}
\hline \multicolumn{1}{c}{ Variabel } & $\begin{array}{c}\text { Average Variance Extracted } \\
\text { (AVE) }(>\mathbf{0 , 5})\end{array}$ \\
\hline Positive Technology Readiness & 0,522 \\
\hline Negative Positive Readiness & 0,548 \\
\hline Perceived Usefulness & 0,644 \\
\hline Perceived Ease of Use & 0,797 \\
\hline Intention to Use & 0,833 \\
\hline
\end{tabular}

Berdasarkan hasil yang ada di Tabel 3, semua konstruk variabel memiliki nilai AVE diatas 0,5 sehingga dapat disimpulkan kelompok item atau kelompok indikator yang mengukur setiap konstruk bersatu atau memiliki validitas konvergen.

Kemudian untuk mengetahui realibilitas dari setiap konstruk dalam, dilakukan dengan melihat nilai composite reliability dan cronbach alpha dari tiap konstruk. Variabel laten atau konstruk dapat dikatakan reliabel jika memiliki nilai cronbach alpha $(\mathrm{CR})$ lebih dari 0,70 .

Tabel 4. Tabel Composite Reliability dan Cronbach Alpha 5

\begin{tabular}{lcr}
\hline \multicolumn{1}{c}{ Variabel } & $\begin{array}{c}\text { Conbach's } \\
\text { Alpha } \\
(>\mathbf{0 , 7})\end{array}$ & $\begin{array}{l}\text { Composite } \\
\text { Reliability } \\
(>\mathbf{0 , 7})\end{array}$ \\
\hline Positive Technology Readiness & 0,773 & $0,844$. \\
\hline Negative Positive Readiness & 0,837 & 0,878 \\
\hline Perceived Usefulness & 0,914 & 0,940 \\
\hline Perceived Ease of Use & 0,817 & 0,878 \\
\hline Intention to Use & 0,933 & 0,952 \\
\hline
\end{tabular}

Berdasarkan Tabel 4, nilai yang ada dalam composite reliability dan juga cronbach alpha, memperlihatkan bahwa masing-masing variabel laten memiliki nilai diatas 0,70 semua. Maka kesimpulannya adalah bahwa seluruh konstruk yang digunakan dalam model penelitian ini memiliki nilai realibilitas yang baik.

Alat analisis yang berfungsi untuk melihat seberapa besar proporsi yang diberikan untuk konstruk endogen dari tiap konstruk eksogen atau faktor-faktor prediktornya merupakan pengertian dari R-square [28]. Jika dalam suatu pemodelan nilai $R$-square lebih dari 0,20 , maka penelitian tersebut berhasil menjelaskan sebuah penelitian.

\section{Tabel 5. Nilai $R$-Square dan $R$-Square Adjusted}

\begin{tabular}{lcr}
\hline Konstruk & $\boldsymbol{R}$-Square & $\begin{array}{c}\text { R-Square } \\
\text { Adjusted }\end{array}$ \\
\hline Intention to Use & 0,417 & 0,410 \\
\hline Perceived Ease of Use & 0,217 & 0,208 \\
\hline Perceived Usefulness & 0,222 & 0,209 \\
\hline
\end{tabular}

Berdasarkan Tabel 5, dari 2 variabel diantaranya Positive Technology Readiness dan Negative Technology Readiness adalah yang diikutsertakan dalam memprediksi adopsi pada sports wearable technology, berhasil memprediksi sebesar $41,7 \%$. Hal ini memperlihatkan bahwa ada 58,3\% yang diterangkan oleh variabel lain diluar variabel dalam model penelitian ini. Sedangkan untuk variabel Perceived Ease of Use, berhasil diprediksikan sebesar $21,7 \%$ artinya masih ada sekitar $78,3 \%$ yang diterangkan oleh variabel lain diluar model penelitian ini. Terakhir, untuk variabel Perceived Usefulness berhasil diprediksi sebesar 22,2\%, artinya masih ada nilai sekitar $77,8 \%$ yang dapat diterangkan oleh variabel lain diluar variabel dalam model penelitian ini, sehingga untuk penelitian selanjutnya dapat dilakukan penambahan variabel lain untuk dapat lebih meningkatkan nilai prediksi pengaruhnya.

Nilai path coefficient memiliki tujuan untuk melihat apakah dalam suatu konstruk endogen akan memiliki 
pengaruh atau tidak berpengaruh serta untuk bagaimana arah relasi yang dimilikinya. Sedangkan t-statistik atau $t$-value merupakan nilai yang didapatkan dari hasil bootstrapping. Dimana nilai Path coefficients harus memiliki t-value yang lebih besar dari 1,96, berdasarkan t-tabel dengan confidence level 0,05 atau $5 \%$, yang berarti signifikan.

Tabel 6. Nilai Path Coefficient dan T-Statistics

\begin{tabular}{lrrrl}
\hline & $\begin{array}{c}\text { Path } \\
\text { Coefficients }\end{array}$ & \multicolumn{1}{c}{$\begin{array}{c}\boldsymbol{T} \text { Statistics } \\
\text { Values }\end{array}$} & Keterangan \\
\hline $\begin{array}{l}P T R \rightarrow \\
P E O U\end{array}$ & 0,473 & 9,251 & 0,0000 & H1a diterima \\
\hline $\begin{array}{r}P T R \rightarrow P U \\
\text { NTR } \rightarrow\end{array}$ & 0,018 & 0,239 & 0,811 & H1b ditolak \\
\hline $\begin{array}{l}P E O U \\
N T R \rightarrow P U\end{array}$ & 0,066 & 0,686 & 0,493 & H2a ditolak \\
\hline $\begin{array}{l}P E O U \rightarrow \\
P U\end{array}$ & $-0,160$ & 2,032 & 0,043 & H2b diterima \\
\hline $\begin{array}{l}P E O U \rightarrow \\
I N T\end{array}$ & 0,431 & 5,615 & 0,0000 & H3 diterima \\
\hline $\begin{array}{l}P U \rightarrow \\
I N T\end{array}$ & 0,460 & 7,155 & 0,0000 & H4 diterima \\
\hline
\end{tabular}

Melalui Tabel 6, dapat dilihat bahwa terdapat 5 hipotesis yang ada dalam penelitian ini. Dimana H1b dan H2a ditolak karena nilai $p$-value lebih besar pada 5\% level signifikan. Sedangkan untuk hipotesis lainnya, dinyatakan diterima karena nilainya lebih kecil dari $5 \%$.

Pada Tabel 6, nilai path coefficient hubungan antara PTR terhadap PEOU dalam hipotesis H1a diterima dan signifikan. Hasil signifikan memiliki arti bahwa sports wearable technology mudah digunakan dalam keseharian pengguna terutama saat mereka berolahraga. Maka salah satu alasan pengguna mengadopsi teknologi tersebut karena pengguna memiliki penilaian positif terhadap teknologi tersebut dan penggunaannya sangat mudah terutama saat berolahraga. Artinya bahwa ketika faktor optimism dan innovativeness yang dimiliki oleh setiap individu terhadap sports wearable technology meningkat, maka penilaian para pengguna terhadap teknologi tersebut pun juga positif. Generasi millennial dalam penelitian ini adalah responden yang paling banyak mengisi kuesioner dalam penelitian ini. Hal ini sejalan dengan karakter yang dimiliki oleh mereka dimana salah satunya mereka memiliki gaya hidup yang serba cepat, praktis ditambah dengan mereka memiliki pemikiran terbuka serta mudah beradaptasi pada suatu teknologi terbaru yang kekinian. Jika dilihat dari sisi Technology Readiness, responden laki-laki dalam penelitian ini memiliki karakter explorers dimana mereka relatif mudah untuk tertarik mengenai suatu produk berbasis teknologi terbaru.

Kemudian untuk hubungan antara PTR dengan PU dalam hipotesis $\mathrm{H} 1 \mathrm{~b}$ adalah ditolak dan tidak signifikan, namun memiliki arah hubungan yang positif. Hal ini menunjukkan bahwa jika penilaian yang positif dari pengguna terhadap sports wearable technology yang digunakan, maka semakin tinggi juga penilaian mereka terhadap pemanfaatan yang ditawarkan oleh sports wearable technology atau dengan kata lain mereka tidak memiliki hambatan dalam merasakan manfaat dari teknologi tersebut. Namun secara statistik, arah hubungannya tidak berpengaruh. Hasil signifikan pada sebuah hubungan memiliki arti bahwa suatu teknologi harusnya memiliki pengaruh yang baik dalam keseharian mereka terutama dalam berolahraga. Maka kesimpulannya adalah pengguna memiliki penilaian yang positif terhadap penggunaan sports wearable technology namun manfaat yang ditawarkan pada teknologi tersebut tidak berpengaruh atau tidak dirasakan secara sadar oleh penggunanya, terlebih saat mereka berolahraga.

Hipotesis H2a dimana didalamnya adalah hubungan antara NTR dengan PEOU adalah ditolak dan tidak signifikan, namun memiliki nilai hubungan yang positif. Arah hubungan positif ini menunjukkan bahwa semakin tinggi nilai NTR maka semakin tinggi nilai PEOU yang dirasakan oleh penguna sport wearable technology. Namun, nilai korelasi yang dihasilkan adalah tidak signifikan atau tidak berpengaruh sama sekali. Kesimpulannya pada sampel penelitian ini tidak berlaku untuk keseluruhan populasi, sehingga hipotesis ditolak. Kemungkinan tidak signifikan dan tidak memiliki nilai yang negatif terhadap PEOU adalah karena pengguna di Indonesia terutama pada generasi millennial dan laki-laki memiliki penilaian/sikap positif yang besar mengenai fitur kemudahan yang diberikan dari teknologi tersebut dibanding dari penilaian negatif responden. Arti lainnya yang bisa diberi kesimpulan adalah faktor discomfort dan insecurity yang ada dalam Negative Technology Readiness terhadap Perceived Ease of Use pun juga tidak sama sekali dirasakan oleh pengguna.

Berdasarkan Tabel 6, nilai path coefficient hubungan antara NTR dengan PU (hipotesis H2b diterima) berpengaruh signifikan dan arah hubungan antara kedua variabel tersebut adalah negative. Hal ini menunjukkan jika penilaian negatif yang ada dalam pribadi pengguna terhadap sports wearable technology maka nilai Perceived Usefulness yang ada di dalam sports wearable technology akan menurun. Hasil signifikan negatif memiliki arti bahwa pengguna masih merasakan insecurity dan discomfort saat mereka masih menggunakan sports wearable technology terutama saat mereka saat berolahraga, sehingga mereka tidak bisa menerima pemanfaatan yang bisa saja bisa memperbaiki intensitas dan gaya hidup berolahraga mereka.

Kemudian untuk hubungan antara PEOU dengan PU dalam hipotesis $\mathrm{H} 3$ adalah diterima dan signifikan, serta memiliki arah hubungan yang positif. Arah hubungan yang positif dalam model penerimaan teknologi ini memberikan arti bahwa semakin tinggi Perceived Ease of Use maka akan diikuti dengan adanya peningkatan pada Perceived Usefulness. Adanya hubungan yang signifikan antar dua variabel ini menunjukkan bahwa hasil hipotesisnya dapat diberlakukan kepada seluruh populasi penelitian ini. Selain itu, pengguna sports wearable technology ini di dominasi oleh kaum generasi millennials, sehingga mudah saja bagi mereka untuk beradaptasi dengan teknologi terbaru dengan cepat, ditambah teknologi ini mudah dioperasikan, jelas dan mudah dipahami, less effort, serta mudah digunakan sehingga pemanfaatan yang dirasakan oleh pengguna otomatis mudah dirasakan. Terlebih lagi responden laki-laki merupakan kaum mayoritas pada perkembangan teknologi terbaru dimana mereka memiliki sikap keterbukaan terhadap teknologi 
terbaru serta mereka memang memiliki interest yang tinggi terhadap olahraga, kesehatan dan teknologi kekinian.

Berdasarkan Tabel 6, hubungan antara PEOU dan INT dalam hipotesis $\mathrm{H} 4$ adalah diterima dan signifikan. PEOU memiliki pengaruh positif terhadap nilai INT dari penggunaan sports wearable technology sebagai fitness tracker diterima. Arah korelasi yang positif menunjukkan bahwa semakin mudah pengoperasian suatu teknologi (Perceived Ease of Use) maka akan diikuti dengan peningkatan terhadap pengapdosiannya (Intention to Use). Adanya korelasi yang signifikan antar dua variabel ini memberi arti juga hasil hipotesis tersebut dapat diberlakukan untuk keseluruhan populasi dalam penelitian ini. Artinya, pengguna dalam penelitian ini dapat mudah mengadopsi atau menerima sebuah teknologi karena kemudahan pengoperasiannya lebih dominan dibanding merasakan pemanfaatannya.

Sedangkan untuk hipotesis H5 dimana didalamnya merupakan hubungan antara variabel PU dan INT diterima dan memiliki arti signifikan. Arah hubungan antara PU memiliki pengaruh positif terhadap INT dari penggunaan sports wearable technology sebagai fitness tracker, diterima. Arah korelasi positif ini memiliki makna bahwa semakin tinggi nilai Perceived Usefulness maka akan diikuti dengan peningkatan pada Intention to Use pada pemakaian sports wearable technology. Adanya hubungan yang signifikan antar dua variabel ini menunjukkan bahwa hasil hipotesis tersebut dapat diberlakukan untuk keseluruhan populasi penelitian. Hal ini terjadi karena bahwa fungsionalitas, kegunaan dan kemampuan untuk belajar merupakan beberapa faktor yang penting untuk mengadopsi sebuah sports wearable technology pada kalangan early adopters terutama pada generasi millennial dan kelompok jenis kelamin laki-laki

\section{KESIMPULAN}

Hasil penelitian memberikan hasil bahwa responden laki-laki pada generasi millennials (18-34 tahun) ini memiliki karakter explorers dimana mereka memiliki nilai Positive Technology Readiness lebih tinggi jika dibandingkan dengan nilai Negative Technology Readiness. Terlebih generasi tersebut memiliki hubungan yang positif serta signifikan tinggi terhadap Perceived Ease of Use dibandingkan Perceived Usefulness dari sports wearable technology berdasarkan konsep teori technology acceptance model. Sehingga dapat disimpulkan bahwa, responden di Indonesia yang termasuk generasi millennial merupakan tipe pengguna yang paling mudah untuk menerima sports wearable technology sebagai fitness tracker mereka dari sisi Perceived Ease of Use. Kemudian berdasarkan teori Technology Acceptance Model jika pengguna merasakan kemudahan dalam mengoperasikan teknologi tersebut, maka pengguna akan menerima manfaatnya sehingga mereka memutuskan untuk mengadopsi teknologi tersebut lebih lama dari saat mereka gunakan saat penelitian ini diberlakukan.

Dibandingkan dengan wanita dalam penelitian ini, memiliki karakter kekhawatiran dimana mereka memiliki perasaan tertarik terhadap teknologi tersebut, namun mereka masih khawatir tentang risiko yang dialami mereka dengan menunjukkan rasa ketidaknyamanan (discomfort) dan rasa ketidakamanan (insecurity). Namun mereka senang mengikuti perkembangan tren pada teknologi tersebut melalui media sosial dikarenakan sikap yang dimiliki oleh wanita Indonesia dalam menggunakan teknologi digital terutama untuk berinteraksi di media sosial.

Kedepannya, agar masyarakat dapat merasakan kegunaan dari teknologi ini, pengguna dan masyarakat, harus dinformasikan atau diberikan edukasi lebih mendalam bahwa menggunakan sports wearable technology bukan hanya sekedar tren teknologi. Namun teknologi tersebut dapat membantu mereka menjadi lebih aktif atau intensitas mereka berolahraga bisa menjadi lebih meningkat, durasi berolahraga mereka bisa menjadi lebih lama karena adanya reminder untuk tidak diam di tempat agar bisa menjadi pribadi yang lebih aktif dibanding sebelumnya.

Untuk perusahaan yang bergerak di bidang teknologi ini, merekomendasikan adanya penambahan artikel tentang keuntungan atau tips berolahraga dengan menggunakan sports wearable technology agar pengguna di Indonesia, terutama pada perempuan, agar dapat mengerti dan paham akan fungsi dari teknologi tersebut, sehingga dapat mengurangi kekhawatiran yang ada. Selain itu, perusahaan juga bisa bekerja sama dengan influencer media sosial atau dengan komunitas yang berhubungan dengan olahraga karena media yang paling efektif untuk menargetkan orang Indonesia terutama kelompok jenis kelamin perempuan adalah melalui media sosial dan berdasarkan word of mouth disekitar lingkungannya karena peran tersebut masih berpengaruh kepada para pengguna.

\section{REFERENSI}

[1] Baller, S., Dutta, S. \& Lanvin, B. (2016). The Global Information Technology Report 2016 Innovating in the Digital Economy. World Economic Forum, Geneva.

[2] International Data Corporation. (2019). IDC Forecasts Steady Double-Digit Growth for Wearables as New Capabilities and Use Cases Expand the Market Opportunities. Diakses dari: https://www.idc.com/ getdoc.jsp?containerId=prUS44930019.

[3] Kumar, S. (2017). Technological And Business Perspective of Wearable Technology. Centrial University of Applied Sciences.

[4] Haghi, M., Thurow, K. \& Stoll, R. (2017). Wearable Devices in Medical Internet of Things: Scientific Research and Commercially Available Devices. Healthcare Informatics Research, Vol. 23(1), pp. 4-15. https://doi.org/10.4258/hir.2017.23.1.4.

[5] Rodgers, M.M., Alon, G., Pai, V.M. \& Conroy, R.S. (2019). Wearable Technologies for Active Living and Rehabilitation: Current Research Challenges and Future Opportunities. Journal of Rehabilitation and Assistive Technologies Engineering, Vol. 6, pp. 1-9. https://doi.org/10.1177/2055668319839607.

[6] Lunney, A., Cunningham, N.R. \& Eastin, M.S. (2016). 
Wearable Fitness Technology: a Structural Investigation Into Acceptance and Perceived Fitness Outcomes. Computers in Human Behavior, Vol. 65, pp. 114-120. https://doi.org/10.1016/j.chb.2016.08.007.

[7] Kim, T. \& Chiu, W. (2019). Consumer Acceptance of Sports Wearable Technology: the Role of Technology Readiness. International Journal of Sports Marketing and Sponsorship, Vol. 20(1), pp. 109-126. https://doi.org/10.1108/IJSMS-06-2017-0050.

[8] Henriksen, A., Mikalsen, M.H., Woldaregay, A.Z., Muzny, M., Hartvigsen, G., Hopstock, L.A. \& Grimsgaard, S. (2018). Using Fitness Trackers and Smartwatches to Measure Physical Activity in Research: Analysis of Consumer Wrist-worn Wearables. Journal of Medical Internet Research, Vol. 20(3). https://doi.org/10.2196/jmir.9157.

[9] Jakicic, J.M., Davis, K.K., Rogers, R.J., King, W.C., Marcus, M.D., Helsel, D., Rickman, A.D., Wahed, A.S. \& Belle, S.H. (2016). Effect of Wearable Technology Combined with a Lifestyle Intervention on Long-term Weight Loss: The IDEA Randomized Clinical Trial. JAMA - Journal of the American Medical Association, Vol. 316(11), pp. 1161-1171. https://doi.org/10.1001/ jama.2016.12858

[10] NHCS. (2018). Not Just A Fancy Fitness Tracker Wearable Sensors Help Predict Heart Problems. National Heart Centre Singapore, Vol. 2.

[11] We Are Social \& Hootsuite. (2020). Digital data Indonesia 2020. Diakses dari: https://datareportal.com/ reports/digital-2020-global-digital-overview.

[12] CNN. (2020). Pengguna Internet Kala WFH Corona Meningkat 40 Persen di RI. Diakses dari: https://www.cnnindonesia.com/teknologi/20200408124 947-213-491594/pengguna-internet-kala-wfh-coronameningkat-40-persen-di-ri.

[13] Intelligence, I. A. (2018). Who are the World's Biggest Wearable Tech Buyers? Diakses dari: https://www.ipsos.com/it-it/who-are-worlds-biggestwearable-tech-buyers\#: :text=From the Fitbit to Apple's,Spain\%2C Turkey and the USA.

[14] Statista. (2020). Fitness - Indonesia (Core country: data based on indepth analysis). Statista.Com.

[15] Gartner. (2016). Gartner Survei Shows Wearable Devices Need to Be More Useful.

[16] Lee, J., Kim, D., Ryoo, H.Y. \& Shin, B.S. (2016). Sustainable Wearables: Wearable Technology for Enhancing the Quality of Human Life. Sustainability, Vol. 8(5). https://doi.org/10.3390/su8050466.
[17] Lai, P. (2017). The Literature Review of Technology Adoption Models and Theories for the Novelty Technology. Journal of Information Systems and Technology Management. https://doi.org/10.4301/s1807-17752017000100002

[18] Oh, J.C., Yoon, S.J. \& Chung, N. (2014). The Role of Technology Readiness in Consumers' Adoption of Mobile Internet Services Between South Korea and China. International Journal of Mobile $\begin{array}{lll}\text { Communications, } & \text { Vol. }\end{array}$ https://doi.org/10.1504/IJMC.2014.061460

[19] Venkatesh, V., Morris, M., Davis, G. \& Davis, F. (2003). Technology Acceptance Model - Research. MIS Quarterly.

[20] Lin, C.H., Shin, H.Y. \& Sher, P.J. (2010). Integrating Technology Readiness into Technology Acceptance: The TRAM Model. Psychology \& Marketing.

[21] Perugini, M. \& Bagozzi, R. P. (2001). The Role of Desires and Anticipated Emotions in Goal-directed Behaviours: Broadening and Deepening the Theory of Planned Behaviour. British Journal of Social Psychology, Vol. 40, pp. 79-98. https://doi.org/10.1348/ 014466601164704

[22] Lee, R. \& Bhattacherjee, A. (2011). A Theoretical Framework for Strategic Use of the Web Among Nonprofit Organizations, SAIS 2011 Proceedings.

[23] Godoe, P. \& Johansen, T.S. (2012). Understanding Adoption of New Technologies: Technology Readiness and Technology Acceptance as an Integrated Concept. Journal of European Psychology Students, Vol. 3(1), pp. 38-52. https://doi.org/10.5334/jeps.aq

[24] Sugiyono. (2012). Metode Penelitian Kuantitatif, Kualitatif dan R \& D. Bandung: Alfabeta. https://doi.org/10.1017/CBO9781107415324.004

[25] Creswell, J.W. \& Creswell, J.D. (2018). Research and Design Qualitative, Quantitative and Mixed Methods Approaches. Thousand Oaks California.

[26] Malhotra, N.K. (2007). Marketing Research: An Applied Orientation, 5th Edition. New Jersey, USA: PrenticeHall, Inc.

[27] Kline, R.B. (2015). Principles and Practice of Structural Equation Modelling (4th ed.). Methodology in the Social Sciences.

[28] Ghozali \& Latan. (2015). Partial Least Square SEM (PLS - SEM).

[29] Wolf, C. (2005). Methodological Aspects in CrossNational Research.. 